\title{
The Program "Client's Voice" as a Tool of Business Structure Innovations
}

\author{
Anvar V. Gumerov ${ }^{1}$, Irina V. Mukhomorova ${ }^{2}$, Regina R. Sadykova ${ }^{3}$, Larisa E. Fatikhova ${ }^{4}$, Natalia M. \\ Chikisheva $^{5}$, Lyudmila M. Simonova ${ }^{6}$ \& Elena E. Alenina ${ }^{7}$ \\ ${ }^{1}$ Kazan National Research Technical University named after A. N. Tupolev - KAI, Kazan, Russia \\ ${ }^{2}$ Russian State University of Tourism and Service, Cherkizovo, Russia \\ ${ }^{3}$ Almetyevsk State Oil Institute, Almetyevsk, Russia \\ ${ }^{4}$ Kazan (Volga region) Federal University, Kazan, Russia \\ ${ }^{5}$ Tyumen state University of Architecture and Construction, Tyumen, Russia \\ ${ }^{6}$ Tyumen state University, Tyumen, Russia \\ ${ }^{7}$ Moscow State University of Mechanical Engineering, Moscow, Russia \\ Correspondence: Anvar V. Gumerov, Kazan National Research Technical University named after A.N. Tupolev, \\ 420111, K. Marks Street, 10, Kazan, Russia. E-mail: solo73@inbox.ru
}

Received: May 7, 2015 Accepted: May 16, 2015 Online Published: May 28, 2015

doi:10.5539/jsd.v8n3p263 URL: http://dx.doi.org/10.5539/jsd.v8n3p263

\begin{abstract}
The purpose of this article is aimed at improvement of interaction between a customer and a manufacturer on the basis of quality management methods development in the business structure. The article demonstrates the quality functions' structuring of the final product based on the study of explicit and implicit needs of the client at the products' design stage or its updating. The basis of the presented paper is the ideas of total quality Management, principles of products quality continuous improvement, production losses reduce and lean manufacturing. The article presents the concept of information support of the program "client's voice", which includes the necessary knowledge and information sources, method of information preservation and use, method of information formalizing from the client. This article is intended for business leaders, top Managers, researchers, all who are involved in the process of development and quality control in business organizations.
\end{abstract}

Keywords: business structure, development, quality management, client's voice, methods of quality management

\section{Introduction}

\subsection{Background}

Modern conditions in market economy, the need for continuous improvement of products and services to maintain competitiveness ensure the relevance of quality management, change and implementation of optimal concepts, providing the requirements of quality and customers satisfaction. Long-term operation planning and distribution system in the domestic economy resulted to the fact that so far, the quality is often taken as the compliance to standard or specifications of the products, while for the consumer, quality is satisfaction of his expectations from the made goods (Adler, 2000; Gludkin, 2001, etc.)

Today, no one doubts the fact that the continuous development and innovation is the only way to maintain high rates of development and level of profitability of the enterprise (Adler, 2005; Porter, 2007; Masalimova \& Sabirova, 2015). The search for competitive advantage is the main direction in the formation of enterprise development strategy, as when creating a new product so in the promotion of goods and services. There are goals of expansion, diversification and innovation in the centre of any development strategy of the organization. It is obvious that in the conditions of high competition for goods and services is not enough to produce quality goods to meet the standard, but there is need of constant evaluation of: market conditions; development opportunities/goods development; level of customer satisfaction; consumer needs. 


\subsection{Status of a Problem}

The necessity of resources finding to increase competitiveness of industrial enterprises define researches in the field of product quality loss. On the one hand, the occurrence of waste and some minor amounts of spoilage is an objective trend of production, on the other hand the market competition among manufacturers, both domestic and foreign, the increasing cost of resources and tools of labor, the need to comply with quality standards requires finding ways to reduce the loss of product quality at all stages of the life cycle (Vasilevskaya, 2010).

Modern technology of relationships with customers is based on individual approach and directed generally on the evaluation and improvement of service quality, the use of multi-functional flexible solutions and expansion of services' range for customers, which ultimately leads to the growth of client loyalty (Taguchi, 1986; Yoji, 1996). However, as demonstrated in the theory and practice of customers' satisfaction improving, this process must necessarily involve the client in the goods design or upgrading, if possible, turning client requirements into technical specifications for goods by anticipating future customer requirements, by implementing necessary technical level and the quality level on the period of their production and consumption.

\subsection{Problem of Investigating}

In the current economic conditions there is urgent need in effective implementation of total quality management (TQM - Total Quality Management) system, the basic concept of which lies in sustainable and continuous satisfaction of the consumer, while the consumer is understood as a buyer of the final product, so the next in the chain of the production process (Juran, 1992; Lapidus, 2002; Gorbashko, 2008).

The modern consumer needs to be an interactive participant in the design of goods, since determining the quality of the products at the initial stages of the life cycle in accordance with the needs (latent or expressed) of the consumer it is possible to minimize loss of quality for the remaining phases. This approach allows produce goods not for abstract but for a particular consumer, defining more precisely his needs and opportunities, thus ensuring a market.

\section{Materials and Methods}

\subsection{The Principle of "Continuous Improvement"}

The principle of "continuous improvement" is put almost at all industrial organizations as implemented standards ISO 9001, ISO 14001 and specification OHSAS 18001. The essence of the principle lies in the implementation of the PDCA cycle at the enterprise, as a method of control according to the results of previous actions: plan, do, control, act (PDCA, Deming, 2011). The basis of this cycle is a continuous positive development of the object "continuous improvement".

According to a recognized leader in the field of quality - the Japanese management system, the concept of "quality improvement" was developed in the following stages: stage 1 - compliance with the norm or standard; stage 2 - standardization and compliance with operational requirements; stage 3 - standardization, guaranteed operation and accounting of the purchasing power of the consumer; stage 4 -accounting of the latent needs of the consumer.

It is obviously, that if the offered goods by the enterprise do not meet the needs of the consumer, then the position of producers in the market will decrease. The more fully the goods meets the buyer's need in its consumer properties, the higher its consumption capacity, i.e. the total integrity of its properties, which determines the effective demand. The importance associated with the goods from the point of marketing is the need to design it with a clear focus on pre-identified target group of consumers.

\subsection{QFD the Methodology of Functions 'Structuring of QFD Quality}

The basic idea of this method of quality function structuring is to develop such a system of the business operation in which customers' requirements are considered to be priority in the design and manufacturing of the product (Kume, 1990);

Briefly, the algorithm of this method consists of the following:

- user's (client) requirements for the quality characteristics of a new or modified product (service) are collected, analyzed, and systematized;

-these characteristics are converted into product specifications, in measured (quantitative) units;

- product's project is planned with the available resource constraints of technical and technological parameters;

- methods of production, methods of quality control are established. 
It is obvious that at each stage in case of their lack in development and poor correlation with requirements at all stages of the life cycle consumer value of the product can occur, resulting to the consumer's dissatisfaction with the quality of the produced goods.

In the author's view, the main difficulties of the quality function structuring with respect to the production of goods are: 1) the reliability of customer requirements formalization into product specifications;

2) organization of goods' production with the established requirements in existing industrial conditions at minimal loss of quality (Bragin, 2003; Gorbunova, Gumerov,2012).

To solve this first problem correlation analysis is usually used, determining the close connection of communication between consumer requirements and measurable performance of the product. Typically, calculating the correlation coefficient of the parameters and direction in connection fact with the acceptable correlation coefficient values the requirement is considered to be satisfied and the so-called "house of quality" is built, reflecting the basic properties of the goods and related its technical and technological characteristics.

However, from the point of view of mathematical statistics theory there is no full compliance between changes in functional and effective feature of the studied parameters, and it is necessary to identify not only the correlation but also to model the quality functions, to verify the adequacy of the model and the possibility of its practical use. In this case, the use of correlation analysis, as a tool for measuring of multiple parameter relationships will be the only step in the process of customer requirements formalization, allowing quantify the characteristics of indicators, and not its result.

\section{Results}

\subsection{Formalization of Information Flows in the Field of Product Quality Structuring}

The main task of the technologies QFD is to bring the views of consumers about the quality of services to the manufacturer of the products. Obviously, when implementing QFD technology its limitations, expressed in the need for high quality research of the market, existing and potential customers and their rapidly changing needs become crucial. That is, the formalization of information flows from the consumer to the manufacturer at all stages of the product life cycle is also a process that requires ongoing management.

The volume and importance of information strategy is greatly enhanced, providing improved cost of information and at the same time increasing the risk of possible errors in its implementation. Information support of managerial decision-making, strategic plans implementation must be fulfilled on the external environment analyzing of an industrial enterprise, strategic goals and objectives defining, development choices implementation using all the above mentioned levels of development. The process of information obtaining, converting, analyzing, and using is a priority thing in the work of any industrial enterprise. The implementation of information activities and information using method forms the information behavior, information culture and information production strategy.

Let's define substantial components of information development of industrial enterprise in the field of QFD (Fig.1).

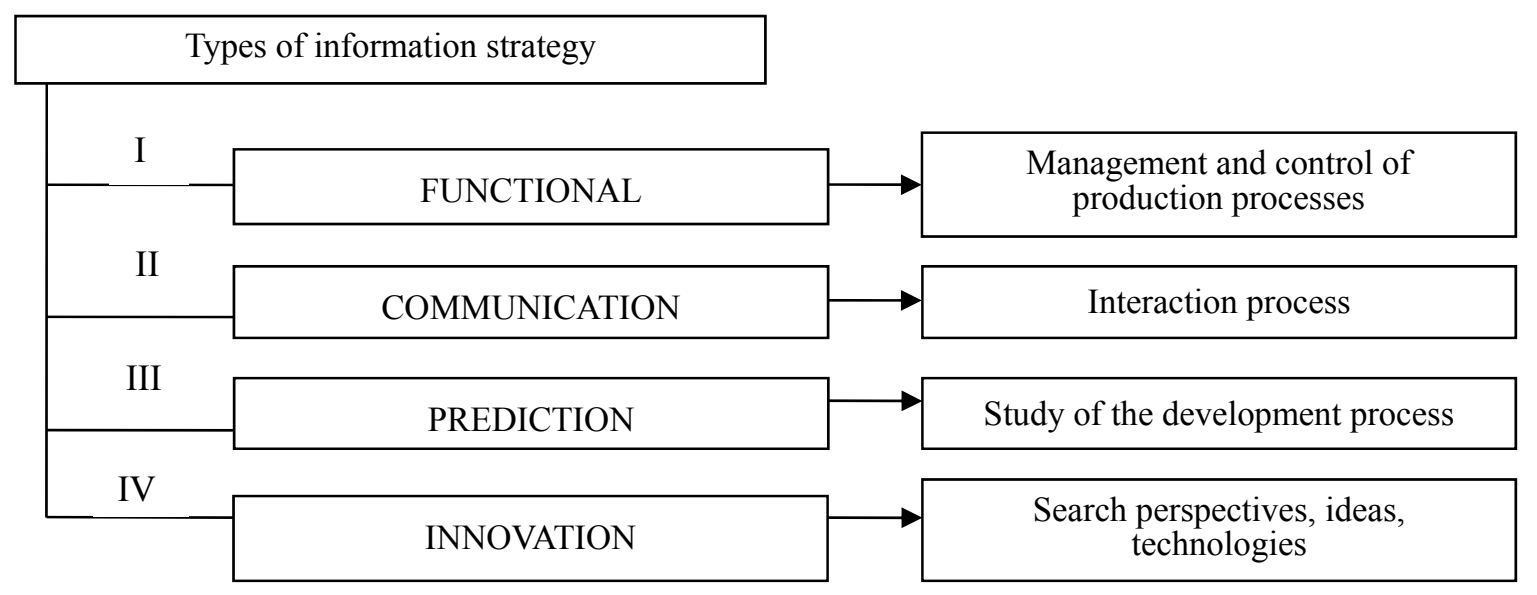

Figure 1. The levels of the enterprise communication strategy 
I. Functional information strategy provides the so-called management information for all activities of the company controlling.

II. Communicative information strategy provides the interaction (communication) of industrial enterprises various structures, services, departments, etc.

III. Predictive information strategy ensures the availability of information, knowledge of possible trends in the development of production processes, scenarios of industry development, changes in customer expectations, market position, etc.

IV. Innovative information strategy aimed at finding ideas and technologies, their development or improvement, ensuring the creation of fundamentally innovative products, ultimately changing conditions of competition.

At each stage of the industrial enterprise product's life cycle the option (type) of the used information strategy should be evaluated. It is important to observe the conditions of necessity and sufficiency of information simultaneously with constant updating and analysis of emerging growth opportunities, new products and competitors. In terms of the need for continuous improvement of industrial enterprises products' quality and the losses reduction, high uncertainty of the market and high competition the development of dual information strategy comes to the forefront - innovation (enabling to learn a new product) and communication (the management of already existing information processes).

3.2 Customer Relationship Management - System as a Resource to Strengthen the Competitive Position of the Enterprise

One of the priorities that improve management efficiency and product quality, reduce the loss of quality on the production cycle is the transformation of the information strategy in the direction of full use of information and information technologies as a resource to gain competitive positions but not as a means or instrument.

From the standpoint of the client's participation in the production process there is a need to make continued support and attract customers, develop innovative products and services that provide not only the existing and expected but also hidden needs. Therefore, it is important to define the following criterion components:

- the necessary knowledge and information's ensuring its sources;

- a method of producing, preservation, analysis and using of this knowledge;

- the correspondence between the obtained and adapted knowledge and production activities.

To involve potential consumers of the goods in the process of its production is necessary to organize communication of information among customers who already use the products of this organization, among the clients who refused of the company's production for one reason or another, among consumers, for whom the company products is brand new. Examining these groups of people we can get different points of view on the product, the integrity of which and the technical implementation will enable to satisfy potential buyers better.

Study of the information effect on the considering process of establishing a client's requirements quality allowed formulation of the following conclusion: the correctness of decision-making is influenced by the amount of information. Its drawback puts the system in a position when it has to make decisions without possibilities of correct calculation of the options' maximum number that certainly reduces the probability of making solution which is the best one in this situation. Too much information increases the probability of the best solution selecting. But the time lost on the processing of redundant information is lost time, and the work itself is useless. In addition, an excess of information contributes to the "concealment" of the main information.

The starting point in informational basis shaping of the considered aspect in the client requirements is the motivation, which being in the form of needs, desires, aspirations, goals exerts a selective effect in the analysis and synthesis of all incoming information, and this thing becomes the basis for eliminating redundant information, i.e. the part, which is functionally unrelated and not important for this result. The result of selective information analysis and synthesis is the formation of client requirements' adequate system on the program "the client's voice " that meets a specific point in time.

Let's define the basic functions in building a Customer Relationship Management (CRM) system, which is based on customer's requirements:

1. To ensure timely access with appropriate limits of authority to continually updated information on interaction with the client;

2. To provide access with appropriate limits of authority for regulations governing the production activity;

3. To provide analytical correlation of client and technical specifications; 
4. To monitor the customer requirements' fulfillment;

5. To verify the level of customer's satisfaction with made goods;

6. To establish a system of accounting for reclamation and after-sales customer service;

7. To create conditions for timely updating of information on the client's needs.

\subsection{Principles of CRM Implementation - System in the Framework of the Program "The Client's Voice"}

To implement it the following principles of implementation of the CRM system should be installed:

-The appliance principle ("the customer is always right")- priority of customer requirements for the product;

-The principle of unity, providing the maximum correlation between customer requirements and technical possibilities and the conditions of production;

-The principle of motivation on positive attitude to the product which reflects the natural relationship between participation of the customer in its designing and development and guaranteed sale of this merchandise to the customer;

-The principle of quality level conformity, which expresses requirements for products made in the QMS of an industrial enterprise.

Implementation of this CRM system will ensure optimum use and management of information about clients on the basis of the system and not discrete approaches, when the fragmentation of projects, client databases, standards and requirements is a shortage of valuable and necessary information, lack in comprehension of client requirements and probable needs.

Together with the necessity of designing the most common problems of building a CRM system for customer specific requirements, we should specify its practical value for the management of the program "the client's voice", and, therefore, it is possible to allocate the following values of the information management functions: goal setting; decision-making; organizational and governing; analytical; diagnostic.

Functions' data analysis which information has at different stages of information ensure development for compliance with client's requirements allows us to formulate a number of requirements (adequacy, relevance, objectivity, completeness, accuracy, structure, specificity, clarity, timeliness and continuity) which be met by this information, in order to realize the program "the client's voice " on its basis. Let us consider each of them.

- The adequacy of information. Generated individual properties and values of the personality can be the reason that customers may form different images and representations regarding the same production functions. As a result of this refraction information regarding personal characteristics the models and information images are formed, which are not a depiction of reality. The adequacy level with which this subjective model reflects the real process makes a significant impact on the formation of customer requirements.

- The relevance of the information reflects the property of necessity and sufficiency of information - the excess of information, as well as its deficit, can form an inadequate model of the real situation.

- The objectivity and accuracy of information. In the transmission of information via different communication channels, it is subjected to distortion under the influence of a number of subjective and/or objective reasons, in particular by the characteristics of the person determining its capacity and capabilities in the reception, processing and transmission of information. However, regardless of the nature of the information distortion, such thing are highly undesirable, and, therefore, there is a need to introduce special mechanisms and methods of errors prevention in the system.

-The completeness of information. Information completeness is understood as taking into account of all the interrelated factors that can influence the products of the industrial enterprise. The main sources of a common information framework formation of the program "the client's voice" are an individual client and public needs, including implicit and predictable ones. The omission or lack of information from one or a group of listed sources may result to the

formation of incomplete and distorted (inadequate) representation in the system and, ultimately, promote the adoption of erroneous decisions.

-The specificity of information. The level of information specificity for the program "the client's voice" determines the range of consumers - it is either directly the buyer of products, using products when implementing the production or life activities, or consumer of the products in the value chain of an industrial enterprise, when the requirements are formed depending on stringent specifications. 
-Clarity of information. Any information performs managerial role only when all the contents of the information received is understood. The content should be presented in the most readable for comprehension and analysis form.

- The availability of information is determined by the available sources of information, which is generated by a set of client requirements received from existing and/or potential customers.

- Timeliness of information and continuity act as procedural and temporal characteristics and for justified decisions adoption have a decisive role. Information which latecomers and received "after the fact", in the best case does not affect the set of generated customer requirements. Information which premature as a rule, unreliable, needs further validation, and therefore is redundant, complicating the extraction of the most important information. Timeliness of information is most important for dynamically changing systems, especially those, which in the composition are affected by the human factor. Continuity of information prevents uncontrolled stages of the process, possible omissions of the analyzed factors.

- Structured information. Multivariable nature of economic information hinders its processing if it is not presented in a structured way. Each element in information structure has a particular destination in the system of the requirements for the product and is consistent with the "objectives tree" of this system.

The basis of such regulation is information of various kinds: the external environment and its objects, about the internal state of the system, etc.

\subsection{Information Ensuring of Compliance with Client Requirements in the "Client's Voice"}

The need for continuous improvement of industrial enterprises products with the purpose of maintaining and advancing competitiveness, ensure quality requirements and customer satisfaction is claimed in embedded in almost all domestic enterprises standard ISO 9001:2008. Information ensuring compliance with client quality requirements to products includes implementation of the following stages (Fig.2.).

The study of the composition and basic characteristics of information needs

The study of the tasks spectrum in the process of working with clients

The definition of information sources and requirements to it from the point of view of the information characteristics

The complete set of information indicators, methods of identifying, obtaining

Processing of the received information, evaluation of its characteristics, classification

The analysis of the information received from the client

Documental fixation of the identified information

Information transfer to controlling structures for further use

Figure 2. The stages of information ensure development for compliance with client requirements in the "client's voice" program

Thus, the generated information strategy of client requirements (the "client's Voice") consists of the following objects:

1. In terms of the need for continuous improvement of product quality it is necessary to transform the information strategy of an industrial enterprise in the direction of full information and information technologies 
use as a resource to strengthen competitive positions, and not as a means or instrument.

2. The modern consumer needs to be an interactive participant in the design of goods, since determining the quality of the products at the initial stages of the life cycle in accordance with the consumer's needs (latent or expressed) it is possible to minimize loss of quality for the remaining phases.

3. It is necessary to expand technology relationship with clients, directed generally to the evaluation and improvement of service quality towards the development of flexible solutions to structure quality functions of products or services.

4. To develop the technology information support for quality functions' structuring, which is built with the obligatory account of the information properties: the adequacy, relevance, objectivity, completeness, accuracy, structure, specificity, clarity, timeliness and continuity.

5. To perform selection and evaluation of information sources, which determine the implementation of the program "the client's voice", while the requirements for information sources are similar with the requirements to the information itself.

6. The simulation implementation of the industrial enterprise products quality functions taking into account the implementation of the program "client's voice", that is:

- products quality functions design based on customer requirements;

- pre-sale and sales customer service - products consumer;

- after-sales customer service.

7. To develop information CRM system that allows ensure the scheme formalization of relationships with customers at all stages of product life cycle, to improve responsiveness, and handling of client requests, to ensure the understanding of customer needs, anticipation of their expectations and ensure information transmission in forward and reverse direction at the technological level.

\section{Discussions}

The analysis shows, that the implementation of the information management strategy of relations with clients (CRM system, Customer Relationship Management) is not fulfilled in the quality management system of domestic industrial enterprises in the proper amount: only the maximum allowable level of defects, the results of after-sales service, the number of returns, advertising features, etc. are taken into account meanwhile, the CRM system, the core of which is customer's satisfaction, as a module of an enterprise information system allows to have the formalization of relationships with customers at all stages of the products' life cycle, to improve responsiveness, and client requests handling, to ensure the understanding of customers' needs, to anticipate their expectations and to ensure the transfer of information in the forward and reverse directions.

\section{Conclusions}

Information CRM system concept development for information delivery, processing and control of client's voice is a technological way of ensuring and developing the product quality control and the integration possibility of this system with a product data control module will give the ability to combine the structures of the data about the production processes, which is necessary when implementing process management in the quality management system of the enterprise. The use of the proposed integrated technology will ensure the availability of the production database on products, resources and the processes of its manufacturing, as well as ensure the necessary flow of information to the right people, which is an important aspect for the implementation of the QMS regulations. In this case, information support of "the client's voice" program implementation will include the necessary accurate and complete data on strategically important properties of the produced product, the resources' allocation and the processes' functioning, i.e. the ways to achieve the quality level which was predetermined by the customer and which meets his requirements.

\section{Acknowledgments}

The authors thank all participants of this study for their kind cooperation.

\section{References}

Adler, Y. P. (2000). Quality and the market, or how the organization is configured to provide the requirements customer. Moscow Standards and Quality publishing, 128.

Adler, Y. P. (2005). System Economics Quality. Moscow Standards and Quality publishing, 183.

Akao, Y. (1996). Quality Function Deployment on Total Quality Management and Future Subject. Quality Control, 
$8,55-64$.

Bragin, Y. V., \& Korol'kov, V. F. (2003). Way QFD: the design and manufacture of products based on the expectations of consumers. Yaroslavl: fitball "Quality Center", 240.

Deming, E. (2011). Out of the crisis: a new paradigm of people management systems and processes. Moscow Alpina Publisher publishing, 419.

Gludkin, O. P. (2001). Total Quality Management: Textbook for Universities. Moscow Hotline - Telecom publishing, 600 .

Gorbashko, E. A. (2008). Quality Management. St. Petersburg, Piter publishing, 384.

Gorbunova, N. I., \& Gumerov, A. V. (2012). Information support of the program "voice of the customer" in an industrial plant. Journal of Modern problems of science and education, 4.

Juran, J. M. (1992). Strategic Quality Management. NY McGra-Hill Inc., 346.

Kume, X. (1990). Statistical methods to improve the quality. Moscow Finance and Statistics, 304.

Lapidus, V. A. (2002). Universal quality (TQM) in Russian companies. Moscow News" publishing, 431.

Masalimova, A. R., \& Sabirova, L. L. (2015). Mentors and Trainees Professional Interaction Features at the Modern Enterprises in Russia. Review of European Studies, 7(4), 20-26. http://dx.doi.org/10.5539/res.v7n4p20

Porter, M. (2007). Competitive Strategy. Moscow Alpina Business Books publishing, 453.

Taguchi, G. (1986). Introduction to Quality Engineering. Designing Quality into Products and Processes. Tokyo, Japan: Asian Productivity Organization, 191.

Vasilewskaya, S. V. (2010). Processes IMS: Application Identification. Journal of Methods of Quality Management, 10, 28-33.

\section{Copyrights}

Copyright for this article is retained by the author(s), with first publication rights granted to the journal.

This is an open-access article distributed under the terms and conditions of the Creative Commons Attribution license (http://creativecommons.org/licenses/by/3.0/). 